\title{
Appropriateness of Helicobacter pylori eradication therapy in gastroenterology patients of a tertiary care hospital
}

\author{
Sreerag K. Vijayan ${ }^{1 *}$, Emmanuel James ${ }^{1}$, Ramakrishna P. Venugopal ${ }^{2}$ \\ ${ }^{1}$ Department of Pharmacy Practice, Amrita School of Pharmacy, AIMS Health Science Campus, Amrita Vishwa Vidyapeetham, Kochi 682041, India. \\ ${ }^{2}$ Department of Gastroenterology, Amrita Institute of Medical Sciences and Research Centre, AIMS Health Science Campus, Amrita Vishwa Vidyapeetham, \\ Kochi 682041, India.
}

\begin{tabular}{l}
\hline ARTICLE INFO \\
\hline Received on: 28/08/2019 \\
Accepted on: 18/10/2019 \\
Available online: 03/12/2019 \\
\hline Key words: \\
Amoxicillin, appropriateness \\
of therapy, clarithromycin, \\
gastroenterology patients, \\
H. pylori eradication, \\
levofloxacin, medication \\
adherence, proton pump \\
inhibitors.
\end{tabular}

\begin{abstract}
Recommended and widely used first-line treatment of Helicobacter pylori consists of a proton pump inhibitor, clarithromycin, and amoxicillin/metronidazole. Recent reports suggest an increase in resistance to these antibiotics, especially to clarithromycin which has adversely affected the effectiveness of this standard regimen, hence levofloxacin containing regimens have also been introduced. Our objective was to assess the appropriateness of clarithromycin and levofloxacin containing regimens for $\mathrm{H}$. pylori eradication by considering the factors such as dose, duration of treatment, patient medication adherence, and H. pylori induced symptom relief. In this prospective observational study, 120 patients were enrolled on the basis of $H$. pylori induced symptoms, positive campylobacter-like organism (CLO) test, or histology proven $H$. pylori infection. Besides socio-demographic characteristics, endoscopic findings, CLO test results and H. pylori induced symptom eradication were documented. Majority of the patients $(85.83 \%)$ received an eradication regimen consisting of clarithromycin + amoxicillin + pantoprazole and the remaining patients were prescribed levofloxacin containing regimens. H. pylori eradication regimen containing clarithromycin was more effective in symptom control. Based on both symptom relief and a negative CLO test on treatment completion, only $40 \%$ of the patients received benefit from the regimens. Moreover, overall therapy was unsatisfactory due to inappropriate dose, duration, or sub-optimal adherence.
\end{abstract}

\section{INTRODUCTION}

Helicobacter pylori is a microaerophilic, spiral-shaped, gram-negative bacterium with several flagella for motility. It can grow only at a periplasmic $\mathrm{pH}$ of $6.0-8.5$ though it can stay alive at a $\mathrm{pH}$ of 4.0. One of the known biochemical properties of $H$. pylori is its capability to produce urease, which can hydrolyze gastric urea to release ammonia, and raise the periplasmic $\mathrm{pH}$ to $4.0-6.0$ and thereby protecting the organism from gastric acidity (Marshall et al., 1985). Helicobacter pylori infection is common worldwide and can result in acute or chronic gastritis, peptic ulcer disease, and can also cause mucosa-associated tissue lymphoma. Additionally, H. pylori seems to be associated with functional dyspepsia

\footnotetext{
${ }^{*}$ Corresponding Author

Sreerag Kadamkundil Vijayan, Department of Pharmacy Practice, Amrita School of Pharmacy, Amrita Vishwa Vidyapeetham, Kochi 682041, India.E-mail: sreeragsree07@gmail.com
}

(Chey et al., 2017, Viswanathen et al., 2018). The diagnostic tests for $H$. pylori include both invasive (culture and sensitivity analysis, histology, and rapid urease test) and non-invasive tests (urea breath test, stool antigen test, and serology). Rapid urease test, also known as campylobacter-like organism (CLO) test, is simple and less time-consuming and has a sensitivity of $95 \%$ and specificity of $80 \%-90 \%$ while histology test has a sensitivity of $60 \%-90 \%$ and specificity $>95 \%$ but neither of them gives any data about antibiotic resistance of the organism (Songur et al., 1995).

Recommended and widely used first-line treatment of $H$. pylori consists of a combination of a proton pump inhibitor (PPI), clarithromycin, and amoxicillin/metronidazole (Chey et al., 2017). PPIs raise the gastric $\mathrm{pH}$ and thereby the organism is kept in an active state of cell division which will enable the killing of the bacteria by the antibiotics (Scott et al., 1998). Since the organism is relatively resistant to antibiotics, combinations of antibiotics are necessary. The timing of administration of drugs is also important to obtain a maximum 
therapeutic response, normally anti-secretory agents should be taken half an hour before food (Hatlebakk et al., 2000) and giving antibiotics after meals improves their intra-gastric distribution and prolongs their gastric residence time. However, the timing of antibiotic administration in relation to meals is not so important in H. pylori eradication therapy (Atherton et al., 1994). Medication adherence is the most important factor in $H$. pylori eradication. Poor adherence to therapy is associated with significantly lower levels of eradication. Factors influencing adherence include the complexity and duration of treatment. The opportunity to improve medication adherence exists at every point of contact between the patient and the medical services (Anthony O'Connor et al., 2009).

However, recent reports note a rise in the incidence of resistance to the antibiotics, especially clarithromycin which has adversely affected the effectiveness of the standard regimen (Papastergiou et al., 2014). Levofloxacin regimen consisting of levofloxacin + amoxicillin + pantoprazole was prescribed as a salvage or alternative regimen for $H$. pylori eradication (Myran and Zarbock, 2018). In areas of high clarithromycin resistance, levofloxacin-based and sequential therapy were superior to standard triple therapy as first-line regimens (Molina-Infante et al., 2010). A clinical trial has shown that the triple therapy regimen containing levofloxacin was better than quadruple therapy (Bilardi et al., 2004). The success rate of $70 \%$ observed with such a triple therapy indicates that a 10 day treatment of pantoprazole, amoxicillin, and levofloxacin should be considered in patients who had failed one or more of the other eradication regimens. But a study from Bangladesh showed that the rate of resistance to clarithromycin, metronidazole, and levofloxacin was high in Bangladesh suggesting that triple therapy-based regimen may not be useful as first-line therapy (Aftab et al., 2016).

A study from Gujarat, India showed that $H$. pylori resistance to metronidazole was $83.8 \%$ and that to clarithromycin and amoxicillin was 58.8\% and $72.5 \%$, respectively (Pandya et al., 2014). A recent study from Karnataka, India reported high resistance to metronidazole $(81.4 \%)$ and levofloxacin $(54.9 \%)$ and modest resistance $(20.4 \%)$ to clarithromycin in $H$. pylori strains. Multidrug resistance was shown in $59.3 \%$ of total strains, in which $86.6 \%$ were resistant to at least both metronidazole and levofloxacin (Shetty et al., 2019). Because of the rising frequency of antimicrobial resistance, the management of $H$. pylori infections is a challenge for physicians. The most effective drug was rifabutin and the lowest sensitive drug was metronidazole in an earlier report (Kwon et al., 2001). Worldwide, H. pylori resistance to clarithromycin and levofloxacin has increased during the last 6 years. Many reports of resistance to antimicrobial agents describe a dramatic decrease in the efficacy of antibiotics (Baubie et al., 2019; Gisbert et al., 2015).

Besides antibiotic resistance, the success of H. pylori treatment depends on other factors such as the dose of the antimicrobial drugs, the duration of therapy and patient's medication adherence. In this study, we aimed to assess the appropriateness of various $H$. pylori eradication regimens in gastroenterology patients of a tertiary care hospital by considering the factors such as dose, duration, patient's medication adherence, and $H$. pylori induced symptom eradication after treatment completion.

\section{MATERIALS AND METHODS}

\section{Patient selection}

A total of 176 dyspeptic patients (96 males and 80 females) attending the gastroenterology department of Amrita Institute of Medical Sciences and Research Center (AIMS), Kochi, and receiving an $H$. pylori eradication regimen were screened for confirmation of $H$. pylori infection. A prospective observational follow-up study was then conducted on all the 120 patients who satisfied the inclusion and exclusion criteria (Fig. 1).

\section{Inclusion criteria}

Patients satisfying all the following criteria were included in the study

- Patients undergoing upper endoscopy due to dyspeptic symptoms

- Patients aged 18 to 70 years and treatment-naive for H. pylori eradication

- CLO test positive patients or patients whose antral biopsy showing the presence of $H$. pylori

\section{Exclusion criteria}

Patients with any of the following criteria were excluded from the study

- Patients who had received proton pump inhibitors, H2 receptor antagonists, bismuth salts, or antibiotics during the 4 weeks prior to study enrollment.

- Patients with malignant tumors of the digestive system

- Patients who had undergone gastrointestinal tract surgery

- Patients whose conditions were complicated by severe heart, lung, blood, liver, or kidney dysfunction

- Patients without informed signed consent

Choice of a particular regimen was at the discretion of treating physicians. The study was conducted from September 2018 to February 2019 after receiving approval by the Institutional Ethics Committee of AIMS (IEC-AIMS-2018-PHARM-31 dated $31 / 08 / 2018$ ) and informed signed consent was obtained from all the patients enrolled.

After obtaining socio-demographic and medication history details of the patients, endoscopic findings, CLO test results, histology results of CLO test negative patients, and type of $H$. pylori eradication regimen given were recorded. All the eradication regimens were given on a twice daily basis. The medication adherence of the patients towards $H$. pylori eradication regimens was determined using a medication adherence reporting scale (Lee et al., 2017). Endoscopic findings, CLO test results, and $H$. pylori induced symptoms [dyspepsia, gastro-esophageal reflux disease (GERD), and gastrointestinal (GI) blood loss] after completion of treatment were documented for patients in whom the CLO test was repeated. For all other patients, $H$. pylori induced symptoms (dyspepsia, GERD, and GI blood loss) after completion of treatment were noted. The absence of gastrointestinal symptoms and a negative CLO test on completion of therapy were the end points considered for the effectiveness of the regimens. 


\section{Statistical analysis}

Statistical analysis was performed using IBM statistical package for the social sciences version 20.0 software. Categorical variables were expressed using frequency and percentage. Numerical variables were presented using mean and standard deviation. The effectiveness of different antibiotic regimens was compared, by the chi-square test. A $p$ value of $<0.05$ was considered as statistically significant.

\section{RESULTS AND DISCUSSION}

Our study (Fig. 2) shows that the most commonly prescribed antibiotic regimen for $H$. pylori eradication was HP pantocid $\mathrm{kit}^{\mathbb{R}}$ and most of the patients received it as a first-line therapy. HP pantocid $\mathrm{kit}^{\circledR}$ consists of a fixed-dose combination of clarithromycin $500 \mathrm{mg}+$ amoxicillin $750 \mathrm{mg}+$ pantoprazole 40 mg. American College of Gastroenterology (ACG) clinical

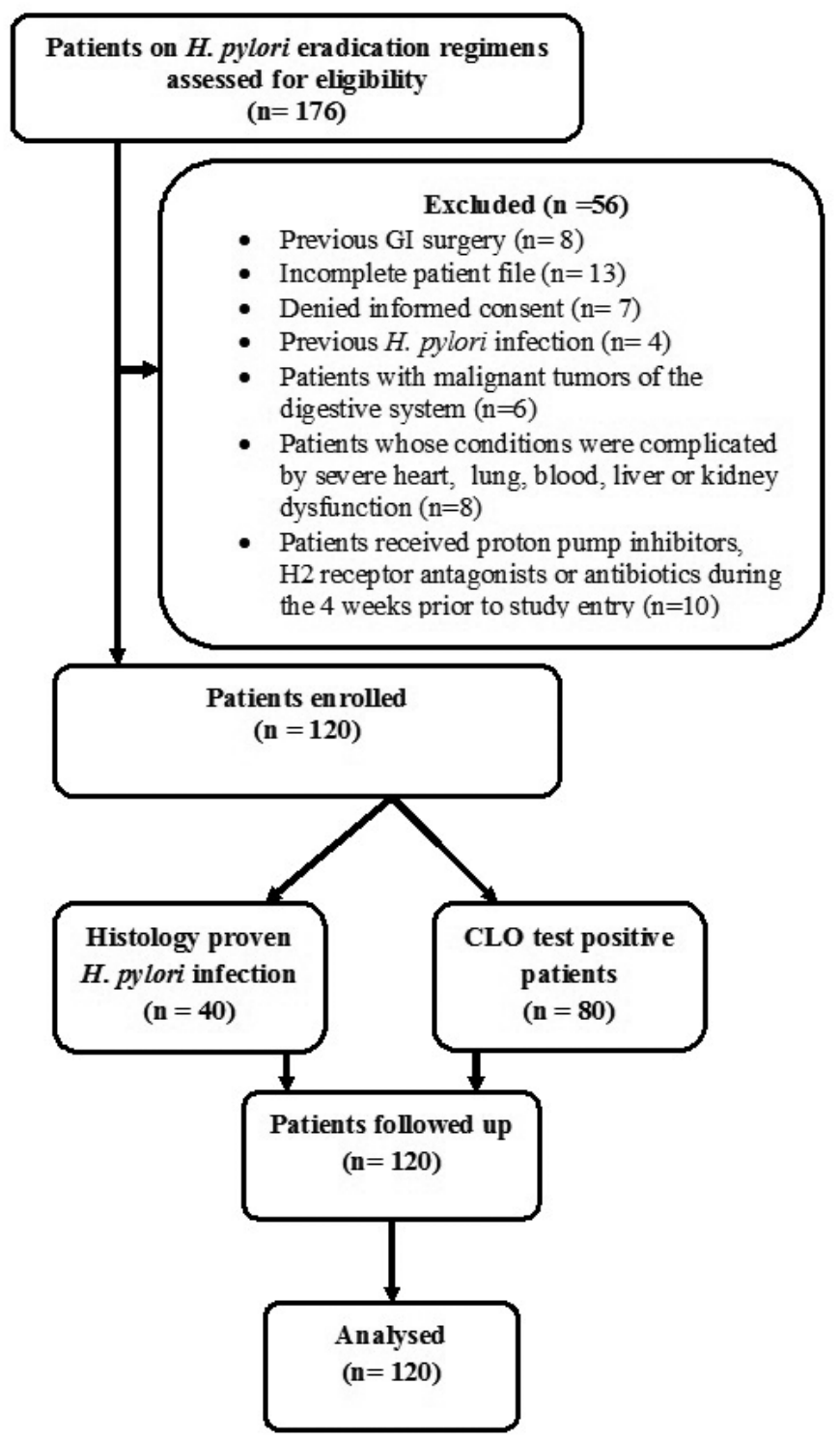

Figure 1. Flow chart of the study process. guidelines recommend the combination of clarithromycin $500 \mathrm{mg}+$ amoxicillin $1 \mathrm{gm}+$ pantoprazole $40 \mathrm{mg}$, but the dose of amoxicillin in HP pantocid $\mathrm{kit}^{\circledR}$ is suboptimal compared to that recommended in the ACG clinical guidelines (Chey et al., 2017). Nexium $H P 7^{\circledR}$, another fixed dose combination pack of clarithromycin, amoxicillin, and esomeprazole for $H$. pylori eradication, has an amoxicillin content of $1 \mathrm{gm}$ instead of $750 \mathrm{mg}$. The guidelines also recommend that the duration of therapy is 14 days, but in our study, $20 \%$ of the patients received HP pantocid $\mathrm{kit}^{\circledR}$ only for 10 days, followed by $5 \%$ receiving it only for 7 days. Hence, $25 \%(30 / 120)$ of our study patients received HP pantocid $\mathrm{kit}^{\mathbb{B}}$ for an inappropriate duration.

Second-line treatment prescribed for $H$. pylori eradication in our study was regimens containing levofloxacin, which were prescribed for $14.17 \%(17 / 120)$ of the patients. According to ACG clinical guidelines, levofloxacin regimen (levofloxacin $250 \mathrm{mg}+$ amoxicillin $1 \mathrm{gm}+$ pantoprazole $40 \mathrm{mg}$ twice daily) should be prescribed for 10-14 days (Chey et al., 2017). This regimen was prescribed appropriately for the patients $(10 / 120,8.33 \%)$ but $3.33 \%(4 / 120)$ of patients received a regimen of levofloxacin $500 \mathrm{mg}+$ metronidazole $500 \mathrm{mg}+$ pantoprazole $40 \mathrm{mg}$ twice daily, which is not recommended by the ACG (Chey et al., 2017). Other levofloxacin regimens received by the patients were levofloxacin $500 \mathrm{mg}+$ amoxicillin $1 \mathrm{~g}+$ pantoprazole $40 \mathrm{mg}$ ) $\times$ bis in die (BD) for 14 days, (levofloxacin $1,000 \mathrm{mg}+$ amoxicillin $250 \mathrm{mg}+$ pantoprazole $40 \mathrm{mg}) \times \mathrm{BD}$ for 10days, and (levofloxacin $250 \mathrm{mg}+$ amoxicillin $500 \mathrm{mg}+$ pantoprazole $40 \mathrm{mg}) \times \mathrm{BD}$ for 14 days. But only one patient $(0.83 \%, 1 / 120)$ each received these regimens. These regimens are also not recommended in the ACG clinical guidelines. A study from Karnataka showed high resistance to metronidazole and levofloxacin and modest clarithromycin resistance in H. pylori strains. Due to this metronidazole, levofloxacin and clarithromycin-based triple therapies are not suitable as first-line treatment in Karnataka, while amoxicillin and tetracycline can be used to eradicate $H$. pylori infection in that region (Shetty et al., 2019). Bismuth containing regimen (bismuth subsalicylate 300 $\mathrm{mg}+$ tetracycline $500 \mathrm{mg}+$ metronidazole $250-500 \mathrm{mg}+$ PPI for 10-14 days, PPI twice daily and all other drugs four times daily) was not prescribed to any of our patients. This may be due to the high cost and non-availability of bismuth salts. Bismuth containing regimens is also endorsed by ACG for $H$. pylori eradication therapy in cases of resistance to clarithromycin.

Endoscopic findings of the study patients are shown in Figure 3. Some patients had more than one finding. Eighty patients were confirmed to have infection by positive CLO test and 40 patients had histologically proven $H$. pylori infection (Fig. 1). Based on $H$. pylori induced symptom eradication, antibiotic regimens prescribed were effective in $59.16 \%(71 / 120)$ of our study patients (Table 1). Of the patients who received HP pantocid $\mathrm{kit}^{\mathbb{B}}$ for 14 days, $83.56 \%(61 / 73)$ were adherent to the prescribed regimen but $57.5 \%(42 / 73)$ had no relief of symptoms (Fig. 4). Thus, the therapeutic response was not satisfactory for most of the patients, this may be related to the inappropriate dose of amoxicillin in HP pantocid $\mathrm{kit}^{\circledR}$ or prior exposure to macrolides leading to clarithromycin resistance. In such situations, bismuth quadruple therapy consisting of a PPI, bismuth, tetracycline, and 


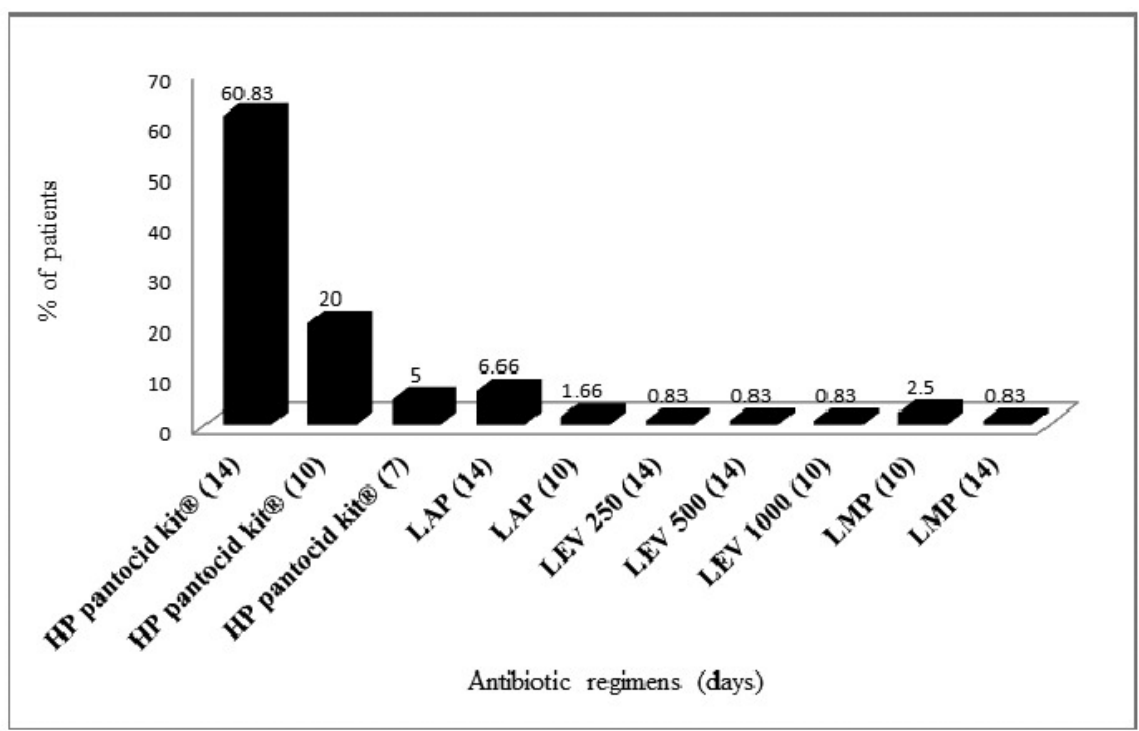

Figure 2. Prescribing pattern of $H$. pylori eradication regimens in the study patients. HP pantocid $\mathrm{kit}^{\mathbb{B}}=$ clarithromycin $500 \mathrm{mg}+$ amoxicillin $750 \mathrm{mg}+$ pantoprazole $40 \mathrm{mg}, \mathrm{LAP}=$ levofloxacin 250 $\mathrm{mg}+$ amoxicillin $1 \mathrm{~g}+$ pantoprazole $40 \mathrm{mg}$, LEV $250=$ levofloxacin $250 \mathrm{mg}+$ amoxicillin $500+$ pantoprazole $40 \mathrm{mg}$, LEV 500 = levofloxacin $500 \mathrm{mg}+$ amoxicillin $1 \mathrm{~g}+$ pantoprazole $40 \mathrm{mg}$, LEV $1000=$ levofloxacin $1,000 \mathrm{mg}+$ amoxicillin $250 \mathrm{mg}+$ pantoprazole $40 \mathrm{mg}, \mathrm{LMP}=$ levofloxacin $500 \mathrm{mg}$ + metronidazole $500 \mathrm{mg}+$ pantoprazole $40 \mathrm{mg}$.

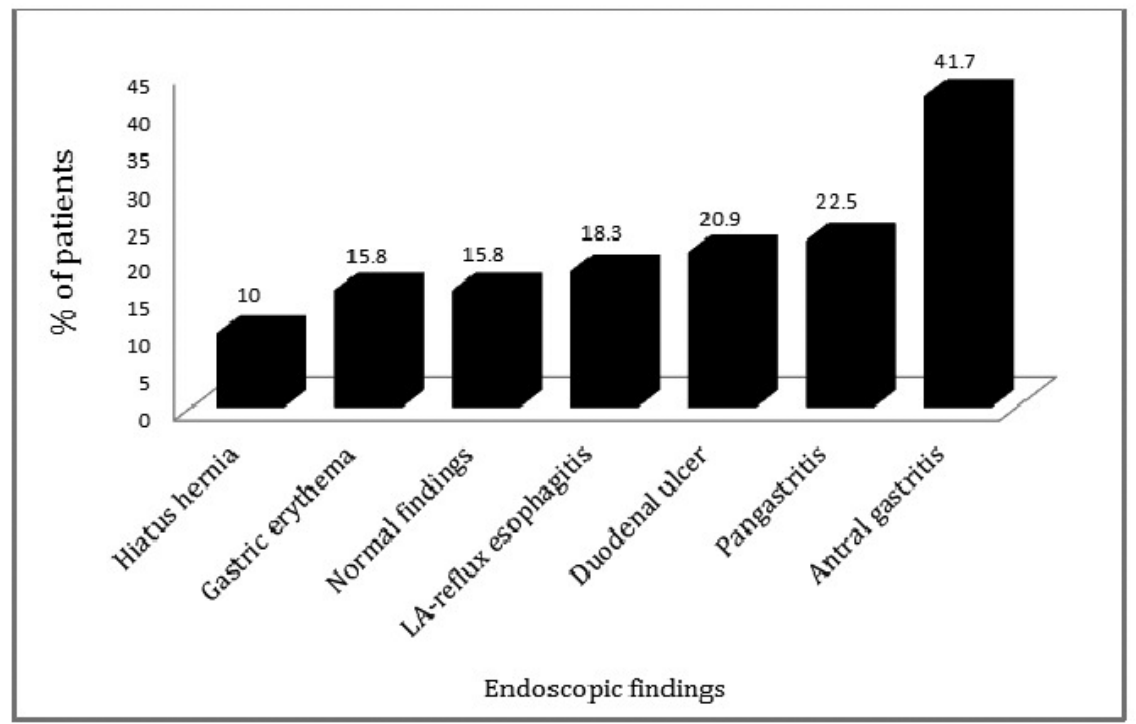

Figure 3. Endoscopic findings of study patients. LA-reflux esophagitis $=$ Los Angeles reflux esophagitis.

a nitroimidazole for 10-14 days or levofloxacin triple therapy consisting of a PPI, levofloxacin, and amoxicillin for 10-14 days are the recommended treatment options by ACG. HP pantocid kit ${ }^{\circledR}$ for a duration of 7-10 days was received by $25 \%(30 / 120)$ of our study patients out of which $33.3 \%$ (10/30) had $H$. pylori induced symptoms after treatment completion and only $10 \%$ (3/30) were non-adherent to the prescribed regimen. The reason for nonimprovement of $H$. pylori induced symptoms may be due to inappropriate duration of therapy, which should have been 14 days instead of 7-10 days or due to inappropriate dose of amoxicillin in
HP pantocid $\mathrm{kit}^{\mathbb{B}}$ or the patients had prior exposure to macrolides for any reason or eradication rate with clarithromycin-based triple therapy was $<85 \%$. In our study, inappropriate dose, duration, and prior exposure to macrolides may be the reason for the noneradication of $H$. pylori induced symptoms.

Among 17 patients who received the second-line regimens containing levofloxacin, 52.9\% (9/17) got relief from H. pylori induced symptoms after treatment completion though $88.23 \%(15 / 17)$ were adherent to the prescribed regimen (Fig. 4). One reason for this may be previous exposure to fluoroquinolones 
(Piddock, 1998). According to ACG guidelines, patients should be enquired about previous antibiotic exposure and this information should be incorporated into the decision-making process, but our study patients were not asked about previous antibiotic exposure and either HP pantocid $\mathrm{kit}^{\mathbb{R}}$ or levofloxacin containing regimens were prescribed empirically without culture and sensitivity or polymerase chain reaction tests to determine resistance pattern of the organism.

In our study, $14.2 \%(17 / 120)$ of the patients were non-adherent to the prescribed $H$. pylori regimens. Medication

Table 1. H. pylori induced symptom eradication after treatment completion $(n=120)$.

\begin{tabular}{lc}
\hline Symptoms & No. $(\%)$ of patients \\
\hline Symptom free & $71(59.16)$ \\
Symptomatic & $49(40.83)$ \\
Dyspepsia & $33(67.34)$ \\
GERD* & $14(28.57)$ \\
GI blood loss** & $2(4)$ \\
\hline
\end{tabular}

${ }^{*} \mathrm{GERD}=$ gastroesophageal reflux disease, ${ }^{* *} \mathrm{GI}$ blood loss $=$ gastro intestinal blood loss. non-adherence is one of the obvious factors leading to failure of therapy. Other factors such as cost, side effects of drugs, and polypharmacy may also lead to non-adherence. Patients prescribed $H$. pylori regimens containing a combination of two antibiotics and a PPI have to take three medications at a time which may reduce adherence.

In this study, 14 patients were CLO test negative on repeat endoscopy after 8 weeks of therapy but eight of those patients had $H$. pylori induced symptoms after treatment completion (Table 2). This shows the drawback of the CLO test for $H$. pylori identification. Baseline CLO test was positive only for 80 patients. The remaining patients were included on the basis of histologically proven $H$. pylori infection and GI symptoms. Hence, histology is a better choice than the CLO test for the detection of $H$. pylori. The results of this study point out that histology should be carried out even on patients who are CLO test negative.

The effectiveness of $H$. pylori eradication regimens prescribed in the study patients was $40 \%$. The majority of the patients prescribed $H$. pylori eradication regimens belonged to the age group of 51-60 years with a mean age of $49.2 \pm 12.94$ years.

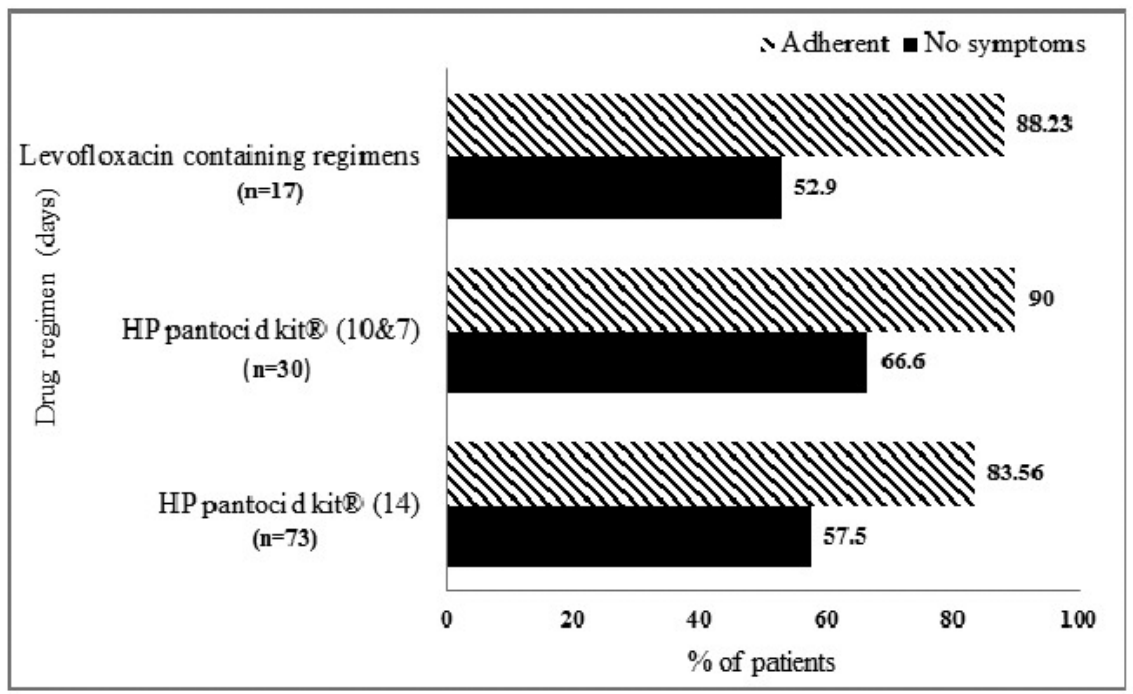

Figure 4. Symptom relief and medication adherence of patients receiving various eradication regimens $\mathrm{HP}$ pantocid $\mathrm{kit}^{\mathbb{}}{ }=$ clarithromycin $500 \mathrm{mg}+$ amoxicillin $750 \mathrm{mg}+$ pantoprazole $40 \mathrm{mg}$. Levofloxacin containing regimens: LAP $=$ levofloxacin $250 \mathrm{mg}+$ amoxicillin $1 \mathrm{~g}+$ pantoprazole $40 \mathrm{mg}$, LEV 250 $=$ levofloxacin $250 \mathrm{mg}+$ amoxicillin $500+$ pantoprazole $40 \mathrm{mg}$, LEV $500=$ levofloxacin $500 \mathrm{mg}+$ amoxicillin $1 \mathrm{~g}+$ pantoprazole $40 \mathrm{mg}$, LEV $1000=$ levofloxacin $1,000 \mathrm{mg}+$ amoxicillin $250 \mathrm{mg}+$ pantoprazole $40 \mathrm{mg}$, LMP = levofloxacin $500 \mathrm{mg}+$ metronidazole $500 \mathrm{mg}+$ pantoprazole $40 \mathrm{mg}$.

Table 2. H. pylori eradication regimens received by the patients and outcome of therapy $(n=15)$.

\begin{tabular}{|c|c|c|c|c|c|c|c|}
\hline \multirow{2}{*}{ H. Pylori regimen } & \multirow{2}{*}{$\begin{array}{c}\text { No. (\%) of patients } \\
\quad(n=15)\end{array}$} & \multicolumn{2}{|c|}{$\begin{array}{c}\text { Repeat CLO test } \\
\text { No. }(\%) \text { of patients }(n=15)\end{array}$} & \multicolumn{2}{|c|}{$\begin{array}{c}\text { GI symptoms } \\
\text { No. }(\%) \text { of patients }(n=15)\end{array}$} & \multicolumn{2}{|c|}{$\begin{array}{c}\text { Medication adherence } \\
\text { No. }(\%) \text { of patients }(n=15)\end{array}$} \\
\hline & & Positive & Negative & Present & Absent & Adherent & Non-adherent \\
\hline Hp pantocid kit $^{\text {ब }}$ & $11(73.3)$ & $1(9)$ & $10(91)$ & $5(45.5)$ & $6(54.5)$ & $10(91)$ & $1(9)$ \\
\hline Second line regimens & $4(26.7)$ & 0 & $4(100)$ & $4(100)$ & 0 & $3(75)$ & $1(25)$ \\
\hline
\end{tabular}

HP pantocid $\mathrm{kit}^{\circledR}=$ clarithromycin $500 \mathrm{mg}+$ amoxicillin $750 \mathrm{mg}+$ pantoprazole $40 \mathrm{mg}$.

Second line regimens

$\mathrm{LAP}=$ levofloxacin $250 \mathrm{mg}+$ amoxicillin $1 \mathrm{~g}+$ pantoprazole $40 \mathrm{mg}$,

LEV $250=$ levofloxacin $250 \mathrm{mg}+$ amoxicillin $500+$ pantoprazole $40 \mathrm{mg}$,

LEV $500=$ levofloxacin $500 \mathrm{mg}+$ amoxicillin $1 \mathrm{~g}+$ pantoprazole $40 \mathrm{mg}$,

LEV $1000=$ levofloxacin $1,000 \mathrm{mg}+$ amoxicillin $250 \mathrm{mg}+$ pantoprazole $40 \mathrm{mg}$,

$\mathrm{LMP}=$ levofloxacin $500 \mathrm{mg}+$ metronidazole $500 \mathrm{mg}+$ pantoprazole $40 \mathrm{mg}$. 
Table 3. HP pantocid kit $^{\circledR}$ versus levofloxacin containing regimen in $H$. pylori induced symptom eradication $(n=120)$.

\begin{tabular}{|c|c|c|c|c|}
\hline \multirow{2}{*}{ H. pylori eradication Regimens } & \multirow{2}{*}{ No. $(\%)$ of patients } & \multicolumn{2}{|c|}{ Symptom eradication No. (\%) of patients } & \multirow{2}{*}{$p$ value (chi-square) } \\
\hline & & Yes $(\%)$ & No $(\%)$ & \\
\hline HP pantocid kit ${ }^{\circledR}$ & $103(85.8)$ & $62(60.2)$ & $41(39.8)$ & 0.573 \\
\hline Levofloxacin containing regimens* & $17(14.2)$ & $9(52.9)$ & $8(47.1)$ & \\
\hline $\begin{array}{l}\text { HP pantocid kit }{ }^{\mathbb{R}}=\text { clarithromycin } 50 \\
* \text { Levofloxacin containing regimens } \\
\text { LAP }=\text { levofloxacin } 250 \mathrm{mg}+\text { amoxic } \\
\text { LEV } 250=\text { levofloxacin } 250 \mathrm{mg}+\text { an } \\
\text { LEV } 500=\text { levofloxacin } 500 \mathrm{mg}+\text { an } \\
\text { LEV } 1000=\text { levofloxacin } 1,000 \mathrm{mg}+ \\
\text { LMP }=\text { levofloxacin } 500 \mathrm{mg}+\text { metron }\end{array}$ & $\begin{array}{l}+ \text { amoxicillin } 750 \mathrm{mg} \\
1 \mathrm{~g}+\text { pantoprazole } 40 \\
\text { illin } 500+\text { pantoprazol } \\
\text { :illin } 1 \mathrm{~g}+\text { pantoprazole } \\
\text { xicillin } 250 \mathrm{mg}+\text { pant } \\
\text { ole } 500 \mathrm{mg}+\text { pantopraz }\end{array}$ & $\begin{array}{l}\text { azole } 40 \mathrm{mg} \text {. } \\
0 \mathrm{mg} \text {, } \\
\text { g. }\end{array}$ & & \\
\hline
\end{tabular}

Occurrence of $H$. pylori infection in developing nations is $80 \%$ in adults over 50 years of age and infected persons normally obtain H. pylori before 10 years of age and grow up with the infection (Chey et al., 2017). In the study patients, the male gender was predominant which may be due to the fact that the majority of the patients undergone endoscopy were males. Though more number of patients using clarithromycin containing regimen got relief of symptoms as compared to levofloxacin containing regimen, the difference was not significant (Table 3). CLO or histology tests could not be performed on all the patients after completion of therapy and culture and sensitivity analysis to determine the resistance pattern of $H$. pylori was not performed and these are limitations of our study.

\section{CONCLUSION}

Most of the patients with dyspeptic symptoms were found to have $H$. pylori infection confirmed by CLO test or histology. Majority of the patients were treated with $H$. pylori eradication regimen containing clarithromycin, amoxicillin, and pantoprazole and got symptom relief. This regimen was found to be more effective than levofloxacin containing regimens in H. pylori symptom eradication. However, overall therapy was unsatisfactory due to inappropriate dose, duration, or sub-optimal adherence. Bismuth containing regimens were not prescribed to any of the patients.

\section{CONFLICT OF INTEREST}

The authors declare that there are no conflicts of interest.

\section{FINANCIAL SUPPORT}

None.

\section{REFERENCES}

Aftab H, Miftahussurur M, Subsomwong P, Ahmed F, AzadKhan AK, Yamaoka Y. Helicobacter pylori antibiotic susceptibility patterns in Bangladesh: emerging levofloxacin resistance. J Infect Dev Ctries, 2016; 10:245-53.

Anthony O'Connor JP, Taneike I, O'Morain C. Improving compliance with Helicobacter pylori eradication therapy: when and how? Ther Adv Gastroenterol, 2009; 5:273-9.

Atherton JC, Hudson N, Kirk GE, HawkeyCK, Spiller RC. Amoxycillin capsules with omeprazole for the eradication of Helicobacter pylori. Assessment of the importance of antibiotic dose timing in relation to meals. Aliment Pharmacol Ther, 1994; 8:495-8.

Baubie K, Shaughnessy C, Kostiuk L, Joseph MV, Safdar N, Singh SK, Siraj D, Sethi A, Keating J. Evaluating antibiotic stewardship in a tertiary care hospital in Kerala, India: a qualitative interview study. BMJ Open, 2019; 9:e026193; doi:10.1136/ bmjopen-2018-026193
Bilardi C, Dulbecco P, Zentilin P, Reglioni S, Iiritano E, Parodi A, Accornero L, Savarino E,Mansi C, Mamone M, Vigneri S, Savarino V. A 10-Day levofloxacin-based therapy in patients with resistant Helicobacter pylori infection: a controlled trial. J Clin Gastroenterol Hepatol, 2004; 2:997-1002.

Chey WD, Leontiadis GI, Howden CW, Moss SF. ACG clinical guideline: treatment of Helicobacter pylori infection. Am J Gastroenterol, 2017; 112:212-38.

Gisbert JP, Romano M, Gravina AG, Solis-Munoz P, Bermejo F, Molina-Infante J, Castro-Fernandez M, Ortuno J, Lucendo AJ, Herranz M, Modolell I, Del Castillo F, Gomez J, Barrio J, Velayos B, Gomez B, Dominguez JL, Miranda A, Martorano M, Algaba A, Pabon M, Angueira T, Fernandez-Salazar L, Federico A, Marin AC, McNicholl AG. Helicobacter pylori second-line rescue therapy with levofloxacin- and bismuth-containing quadruple therapy, after failure of standard triple or non-bismuth quadruple treatments. Aliment Pharmacol Ther, 2015; 41:768-75.

Hatlebakk JG, Katz PO, Camacho-Lobato L, Castell DO. Proton pump inhibitors: better acid suppression when taken before a meal than without a meal. Aliment Pharmacol Ther, 2000; 14:1267-72.

Kwon DH, Lee M, Kim JJ, Kim JG, El-Zaatari FA, Osato MS, Graham DY. Furazolidone and nitrofurantoin resistant Helicobacter pylori: prevalence and role of genes involved in metronidazole resistance. Antimicrob Agents Chemother, 2001; 45:306-8.

Lee CS, Tan JHM, Sankari U, Koh YLE, Tan NC. Assesssing oral medication adherence among patients with type 2 diabetes mellitus treated with polytherapy in a developed Asian community: a cross sectional study. BMJ open, 2017; 7:e016317; doi:10.1136/ bmjopen-2017-016317

Marshall BJ, Armstrong JA, McGechie DB, Glancy RJ. Attempt to fulfill Koch's postulates for pyloric campylobacter. Med J Aust, 1985; $142: 436-9$.

Molina-Infante J, Perez-Gallardo B, Fernandez-Bermejo M, Hernandezalonso M, Vinagre G, Duen AS D, Mateos-Rodriguez JM, Gonzalez-Garcia G, Abadia EG, Gisbert JP. Clinical trial: clarithromycin vs. levofloxacin in first-line triple and sequential regimens for Helicobacter pylori eradication. Aliment Pharmacol Ther, 2010; 31:1077-84.

Myran L, Zarbock SD. Management of Helicobacter pylori infection. US Pharm, 2018; 43:27-32.

Pandya HB, Agravat HH, Patel JS, Sodagar NRK. Emerging antimicrobial resistance pattern of Helicobacter pylori in central Gujarat Indian J Med Microbiol, 2014; 32:408-13.

Papastergiou V, Georgopoulos SD, Karatapanis S. Treatment of Helicobacter pylori infection: past, present and future. World J Gastrointest Pathophysiol, 2014; 5:392-9.

Piddock JVL. Fluoroquinolone resistance, over use of fluoroquinolones in humans and veterinary medicine can breed resistance. BMJ, 1998; 317:1029-30.

Scott D, Weeks D, Melchers K, Sachs G. The life and death of Helicobacter pylori. Gut, 1998; 43:S56-60.

Shetty V, Lamichhane B, Tay CY, Pai GC, Lingadakai R, Balaraju G, Shetty S, Ballal M, Chua EG. High primary resistance to metronidazole and levofloxacin, and a moderate resistance to clarithromycin in Helicobacter pylori isolated from Karnataka patients. Gut Pathog, 2019; 11:21; doi:10.1186/s13099-019-0305-x 
Songur Y, Okai T, Watanabe H, Motoo Y, Sawabu N. Endosonographic evaluation of giant gastric folds. Gastrointest Endosc, $1995 ; 41: 468-74$

Viswananthen VA, Vijayakumar G, Sudevan R. Need of upper GI endoscopy in renal transplant workup patients in a resource limited setting - A cross sectional study from Kerala, South India. Amrita J Med, $2018 ; 14: 25-7$.
How to cite this article:

Vijayan SK, James E, Venugopal RP. Appropriateness of Helicobacter pylori eradication therapy in gastroenterology patients of a tertiary care hospital. J Appl Pharm Sci, 2019; 9(12):129-135. 